\title{
Adaptation of the Local Ghanaian Caldron ("Dadesen") for Drums Shells
}

\author{
${ }^{1}$ Kafui Kwesi Agyeman, ${ }^{2}$ Harold Awuley Quaye, ${ }^{3}$ Frederick Ampah Clement and ${ }^{4}$ Theophilus Agyekum Sarpong \\ 1,2,3,4 Department of Integrated Rural Art and Industry, Faculty of Art, Kwame Nkrumah University of Science and Technology, \\ Kumasi, Ghana
}

Abstract:- The introduction and high patronage of foreign utensils has reduced the demand for the "dadesen" (a traditional aluminium caldron in Ghana). This is seen by this research as threat to the producers. For this reason, the researchers realise the need to diversify the use of the "dadesen" to assure the livelihood of the local artisans who make them and also to save the craft for posterity. This led to a physical analysed of the form which suggested drum shells. This led to a factor analyses of how a drum /shell can be produced from the "dadesen" and subsequently a drum. These were done in consultation with drum carvers and experts from the localities through interviews and observation. Consequently, the researchers arrived at defined means of executing "dadesen" drum shells and subsequently employed the Ghanaian traditional talking drum making process to stretch the animal skin on the metal shell. This led to the production of a pair of talking drums. These drums were thoroughly tried and the sounds were good. It is therefore concluded that the "dadesen" is a potential form for making of drums. This is highly recommended for another genre of drums.

Keywords:- Caldron, “Dadesen”, drum, drum shell, animal skin.

\section{INTRODUCTION}

According to Denisoves (2011), spherical cast-iron pots of different origin were introduced to different parts of Africa. These also become popular in the urban areas of Ghana. And like in other parts of Africa where they were introduced, were also taken up as artisanal trades among the local. But unlike the original produced in cast-iron, they were cast in aluminium. As shown in figure 1, they come in different size for cooking varied quantities of food.

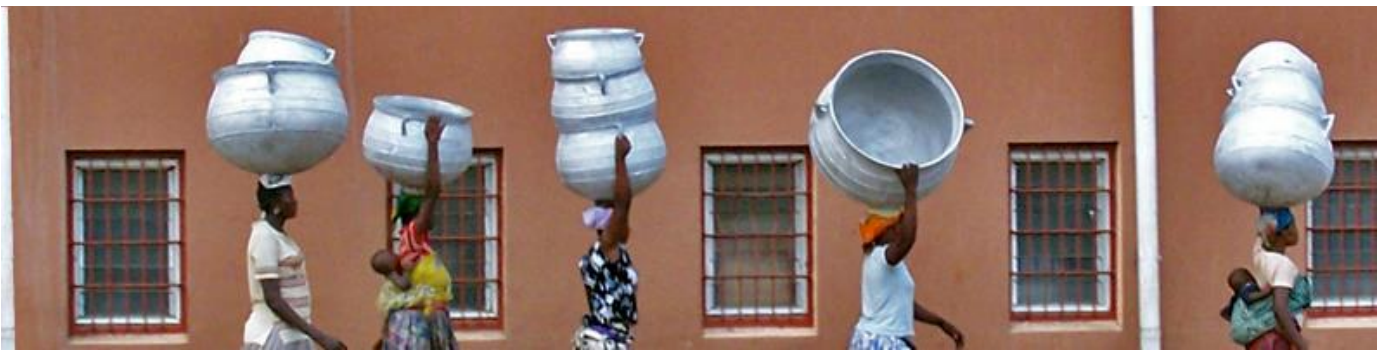

Fig 1:- Women carrying different sizes of the "Dadesen" (benistoves.wordpress.com, 2011)

Moreover, the use this pot has been appreciably been able to stand the test of time due to the uniques of its application to Ghanaian dishes that require the use of the stirring stick stirring (a wooden spatula locally known as the "Banku ta"). This is common in the cooking of Ghanaian food such as "Banku", "Fufuo", "Kokonte" and "Akple" among the different cultures. The Dadesen and the "Banku ta" are shown in figure 2, and the cooking method employing the use of the "Banku ta") also in the figure 3 below.

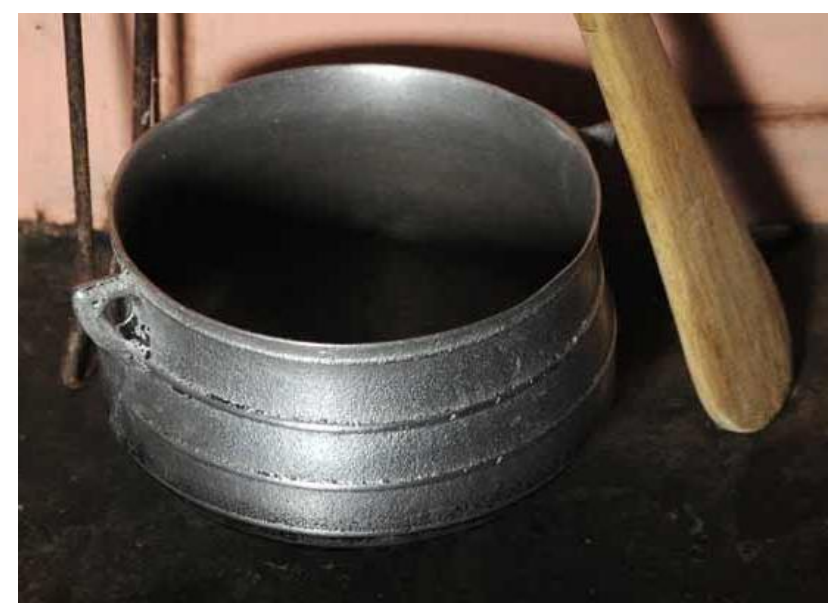

Fig 2:- The "dadesen" with the usual stirring stick ("Banku ta") 


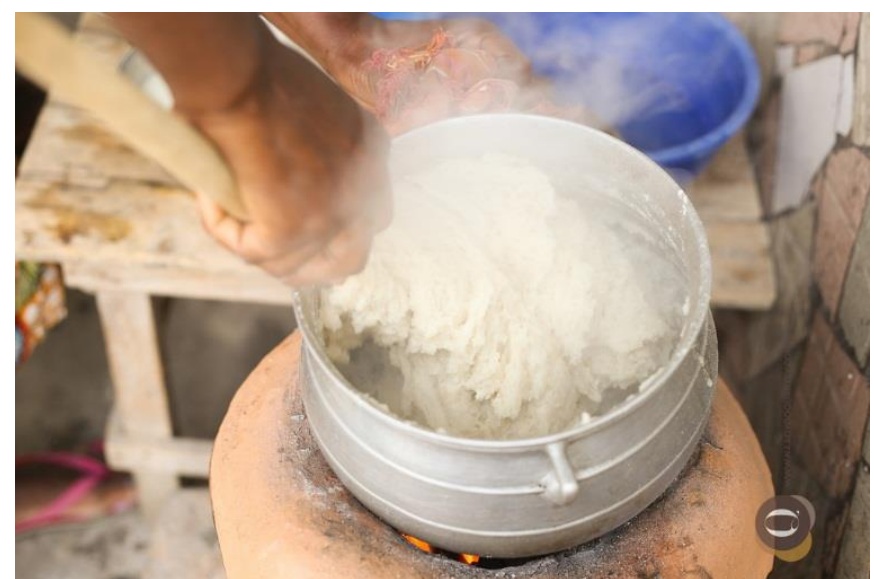

Fig 3:- The "dadesen" with the wooden spatula ("Banku ta") in action

According to Aluminium Bozen (2015) aluminium in Ghana is in abundance. And these are for various types of cooking utensils. The culture of the people of Ghana also include the casting of local utensils and other castings for other local uses as one of her main occupations for the locals. Among these untensils is the local aluminium cooking pot locally known as "Dadesen" by the Akan Tradition. But due to the importation of foreign utensils as well as their production techniques, the rate at which people patronize cast aluminium cooking pots does not relate well to the increasing population. This raises eye brow so far as the business of the artisans involved are concerned. The researcher was motivated to embark on this project to contribute to salvaging the dying industry/business of the cast aluminium pot producers in Ghana. Another reason is that, the drums produced in Ghana, have their materials to be timbers from our limited rain forest. This research is also targeted at contributing to the diversification of drum making materials, to contribute alternatives to the culture of the Ghanaian and related market towards the protection of the fast depleting forest.

Preliminary market survey suggests that, the introduction and high patronage of the foreign utensils produced local and also imported has reduced the demand for the "dadesen". This is seen by the researchers as a threat to the producers. Hence, the need to maintain the "dadesen" business by means of its alternative use. This call for approaches such as, employing the cast aluminium cooking pot as a frame in the making of drum. This is based on the concepts in drums making; factors considered in making drums; and aluminium fabrication techniques.

(Eldridge, 2005), suggest that the forest has never rest due to the long tradition of drums, according to him, drum is the oldest known instrument in the world dating back to $4000 \mathrm{BCE}$ in Egypt in the northeast corner of Africa. It is present throughout every region of Africa playing different roles amongst the various peoples. Also Brendan Mcguigan (2014) stated that drums play an integral role in most of African cultures, there is a diversity of African drums that is truly staging. Many types of African drums have been around for hundreds and thousands of years and have made their way through large portion of the continent. Furthermore, drums are used only for their musical qualities, but also as a means of communication over great distances. The talking drums of Africa are used to imitate the tone patterns of spoken language. Throughout Sri Lankan history, drums have been used for communication between the state and the community, and Sri Lankan drums have a history stretching back over 2500 years.

According to McGuigan (2014), the most well-known of the African drums are the drums known as the talking drums. Although this term may be used to refer to any drum which can have its pitch modulated to sound like words in the local language, it is more commonly used to refer to a set of African drums found in West Africa. These drums come in many shapes, but most commonly are in straight hourglass shape with two leather covered heads.

According to Isaiah (2004), a drum usually consists of a skin, a shell or the body and some mechanism that holds the two together. The skin of the drum is a flexible membrane stretched tightly across the rim of the shell. Traditionally, skins were made out of animal skin, but set drums and some hand drums now use synthetic skins. The skin can be held onto the rim in a variety of ways. Some traditional drums such as the Irish bodhran, use tacks or glue to hold the skin in place. Other use ropes or adjustable metal brackets to attach the skin to the body.

Moreover, these drums are carved in variation of sizes. However, during a marketing survey of the local caldron for marketers and producers, Hadjia(2017), Hannah (2017), Priscilla (2017), Ibrahim (2017), and Ganiho (2017) shared similar views on the rage of sizes regarding the caldrons. According to them, the aluminum caldrons consit of sixteed sizes as follows: $1 / 2,1,1 \frac{1}{2}, 2,3,4,5,6,8$, $10,12,15,20,30,40,50$ and 60.

\section{MATERIALS AND METHOD}

\section{A. Materials}

The cast aluminium cooking pots (dadescn) is the main material used in this project, employed for the shell of the Drum. This pot as illustrated in figure 4, is made of features that are comparable to drum frames. Figure 5 that follows suggests that all the parts of the atuman drums can be seen in the (dadesen) expect the base trunk. This 
including range of sizes of the caldron already mentioned in the introductions is the basis for the selection of the "dadesen" for the drum concept that follows later in this document.

Secondly, the Goat is skin chosen over the many types of animal skin that can be used due to the sharp sound it produces, notwithstanding its malleable nature and availability. Moreover, Raffia was used in the making of the drum ring to hold the goat skin because it is more flexible. Furthermore, the nylon thread was the main material used in rendering the weaves to stretch the goat skin with the aid of the pegs or tuning keys, though leather strips are traditionally used. Pegs also known as the tuning keys were made of wood. This is used to hold the nylon thread for weaving. The quantity that may be used depends on the circumference of the drum. In this case six pieces each per a drum were used.

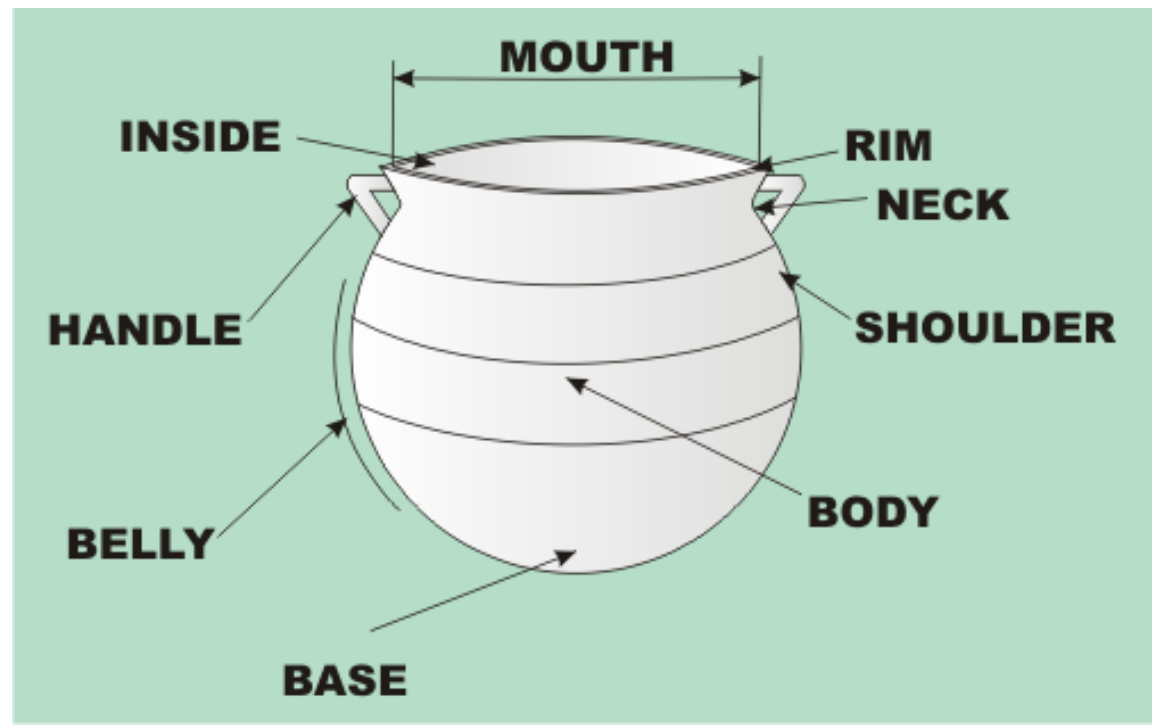

Fig 4:- "Dadesen" showing its parts

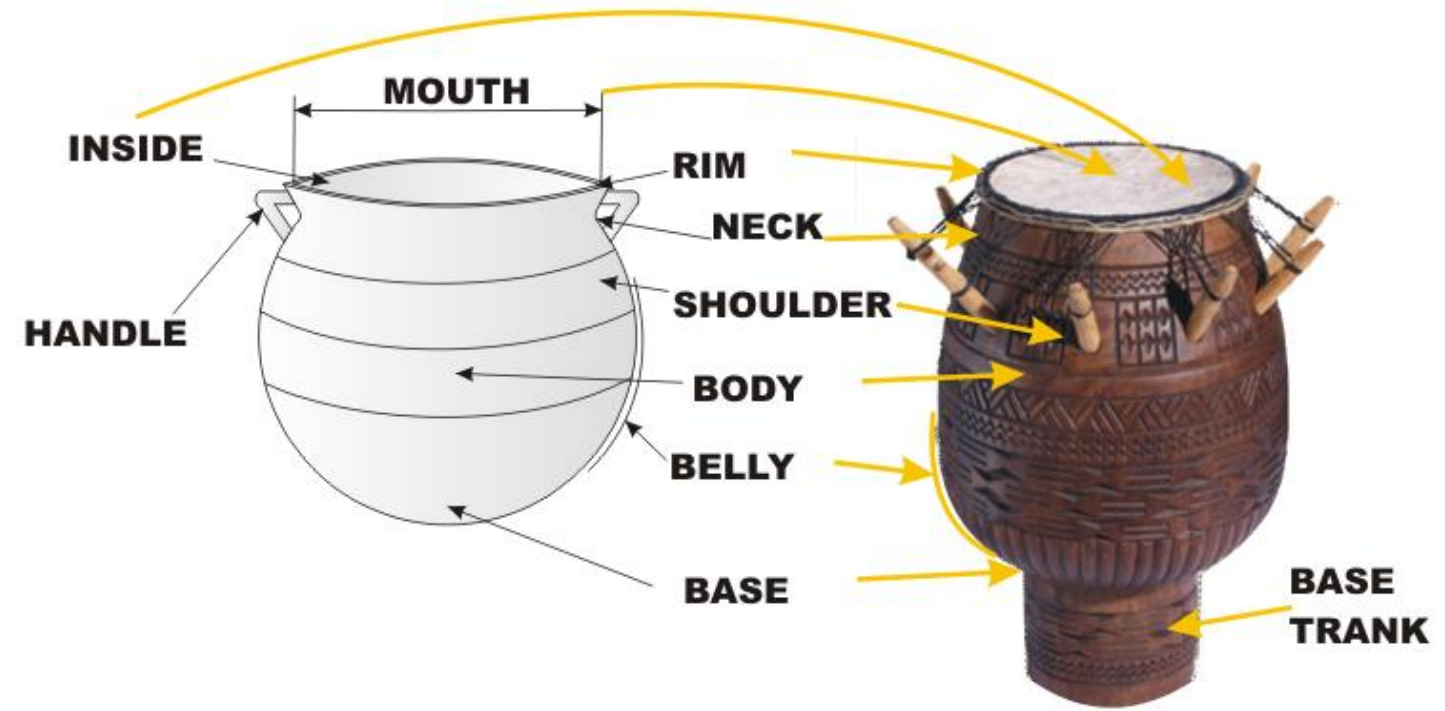

Fig 5:- A comparism between the Dadesen and the Atumpan Drum

\section{B. Methods}

The methods to this research was approached pragmatically, employing the action and experimental designs. In this regard the research in the quest of knowing the intrinsic features of drums, visited eight (8) carving firms and out of these firms twenty-five (25) people were interviewed.
Base on the preliminary interviews and observations as well as the selected "dadesen" to be used, the design process ensued from thumbnail sketches, through selection and refining stages to a final idea. These ideas were characterised by two basic approaches, the use of a single pot as shown in figure 6 and the used of two pots as presented in figure 7 . 
After settling on the final ideas shown in figure 6 regarding the double pot approaches, the idea was developed and refined further to achieve a more definite idea and a picture of the anticipated result as shown in figures 8 and 9 respectively. The final is a simulation results of the expected form using a 3D software.

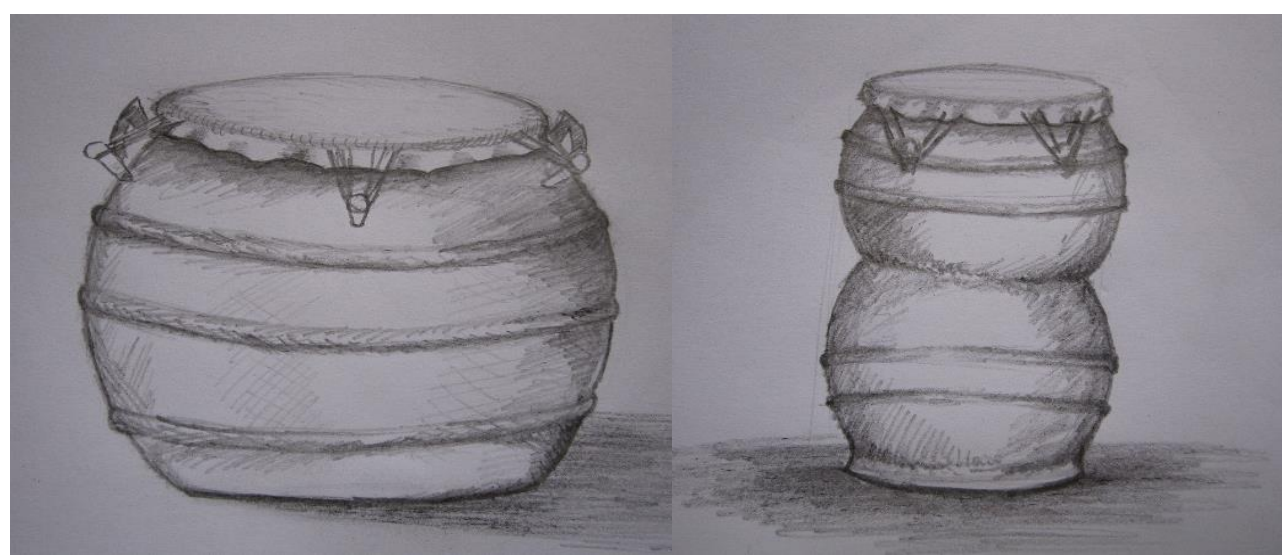

Fig 6:- single pot concept

Fig 7:- Double pot concept one (initial idea)

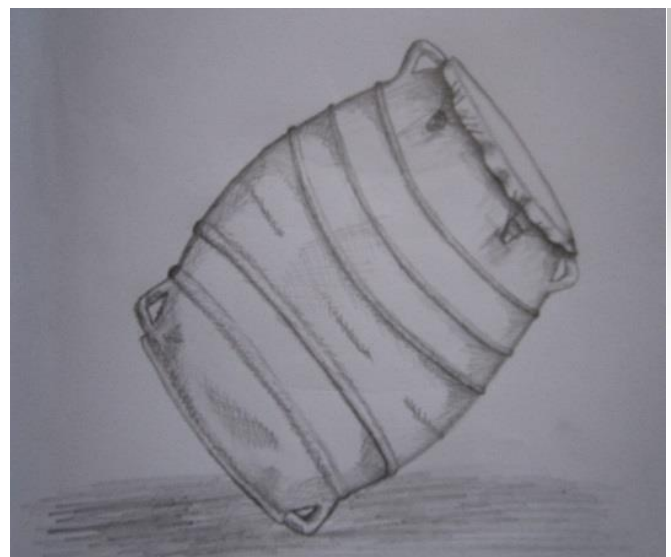

Fig 8:- Double pot concept two (refined idea)

Fig 9:- 3D rendition of the expected form

According to the dictates of the final concept, the four selected pots were carefully cut to remove their bottoms and handles with hacksaw as shown in figure 11. Figure 10B shows the unwanted portions of the pot in black. The "C" show the result after the cutting and "D" the supposed alignment. The bottom was removed in the middle of the curve of the belly to smoothen the curve that is formed when the two parts are joined together. The two properly aligned parts in both cases of the pair were joined through the gas welding process as shown in figure 12 to form the drum frames.

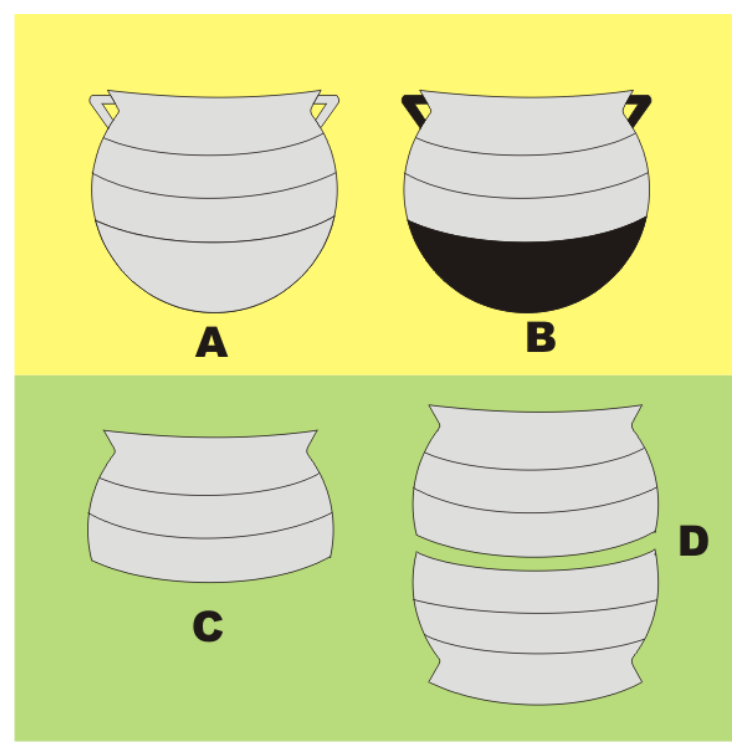

Fig 10:- Some illustrated steps in the drum making process 
ISSN No:-2456-2165

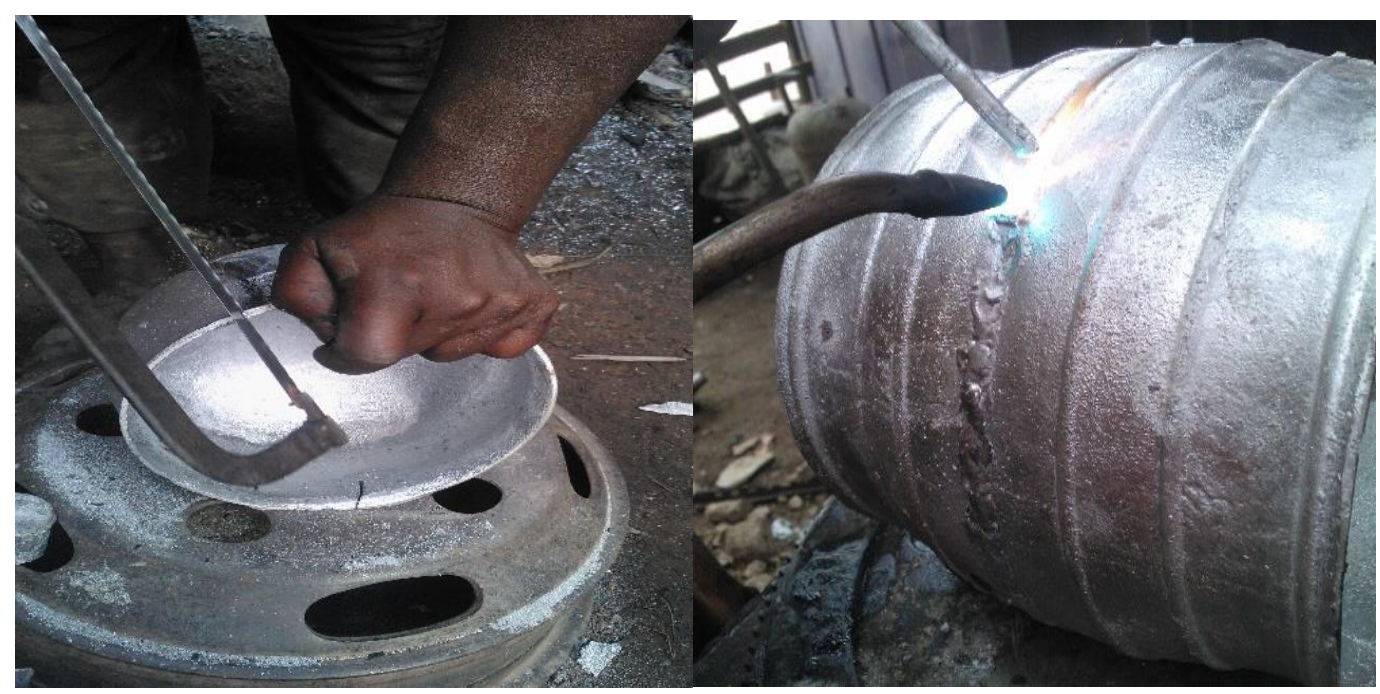

Fig 11:- Cutting of the dadescn

Fig 12:- Welding of the dadescn with gas

The excess welds were then grinded off with the aid of the grinding machine in figure 13 , to smoothen the body to make the surfaces flow. One mouth of the frame was chosen for the covering of the skin. The shoulder to the selected mouth was calculated for proper positioning and equal distances among the pegs. These positions of the pegs were then marked respectively and drilled appropriately as in figure 14. This was done with the drilling machine with an meta drill bit, after which the peg holes were then perfected with the use of the hand file.

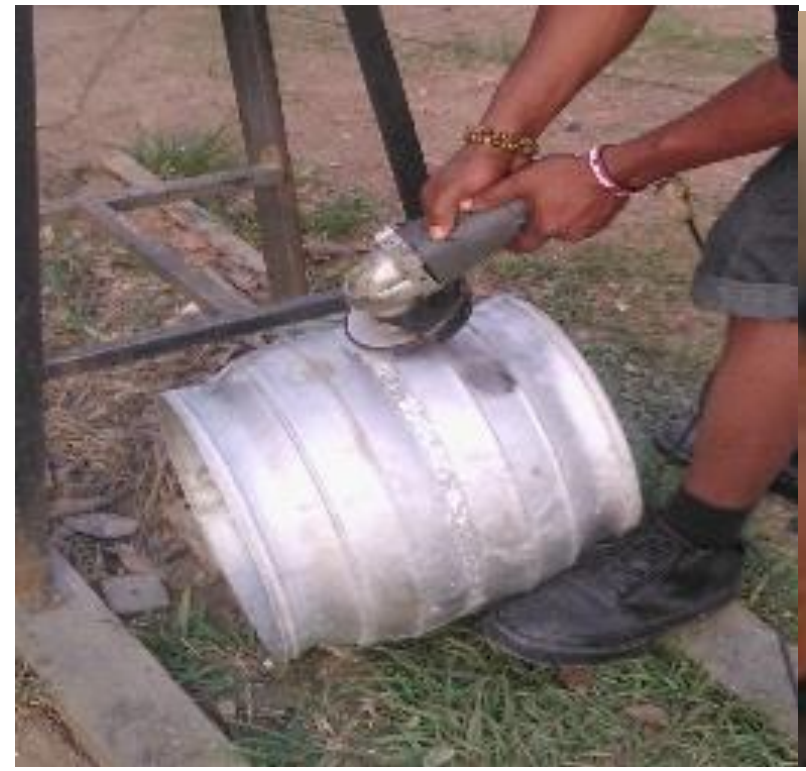

Fig 13:- Grinding of the flux off the frame

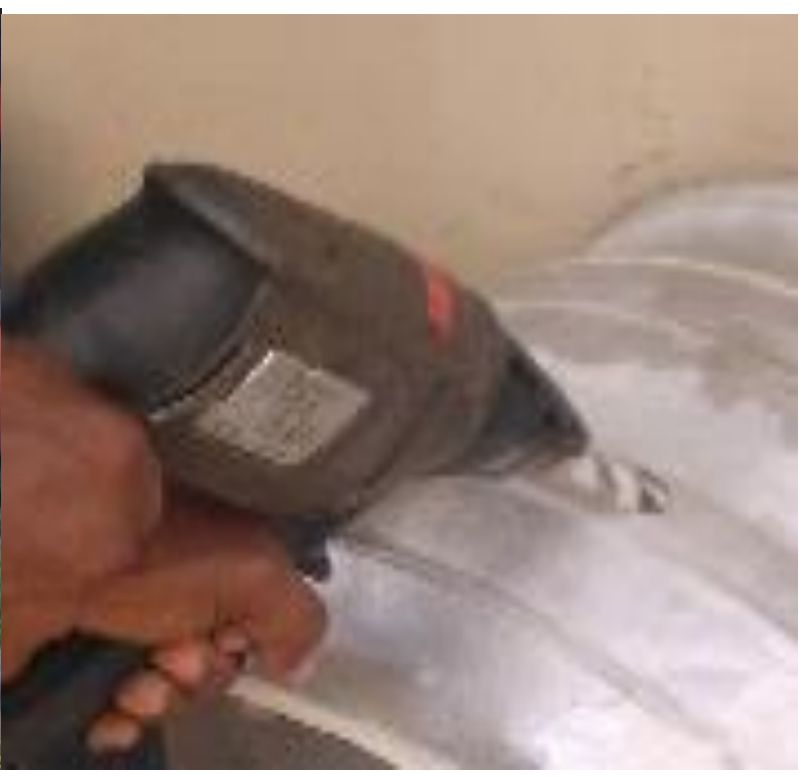

Fig 14:- dilling peg holes

The pegs were shapes into appropriate sizes that fitted into the peg holes on the drum frame as in figure 15 . The goat skin was then cut into the required shape and size, wet with water as in figure 16 to soften it to allow for easier tonging and stretching onto the selected end ring of the "dadesen" shell. 


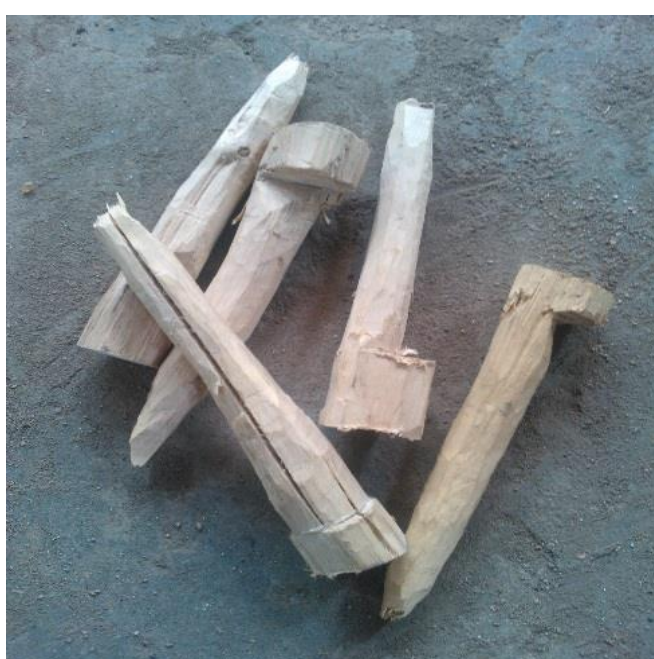

Fig 15:- picture of drum pegs

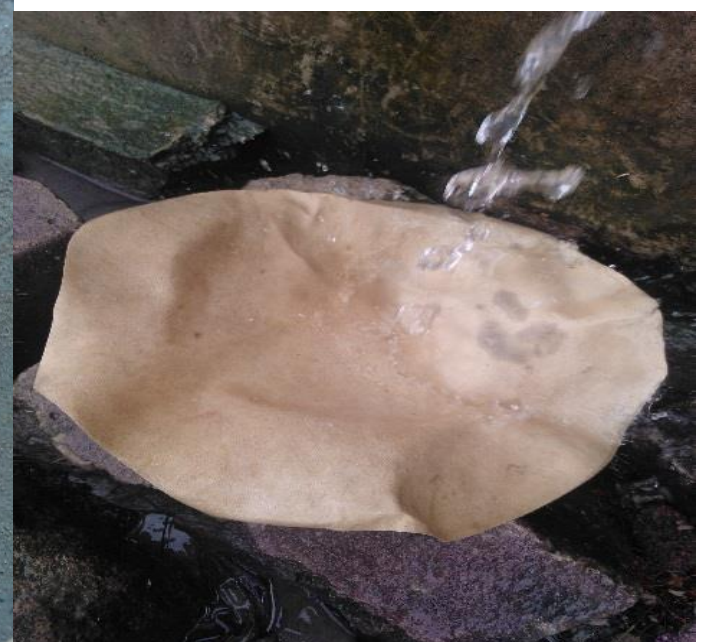

Fig 16:- The goat skin being soaked with water

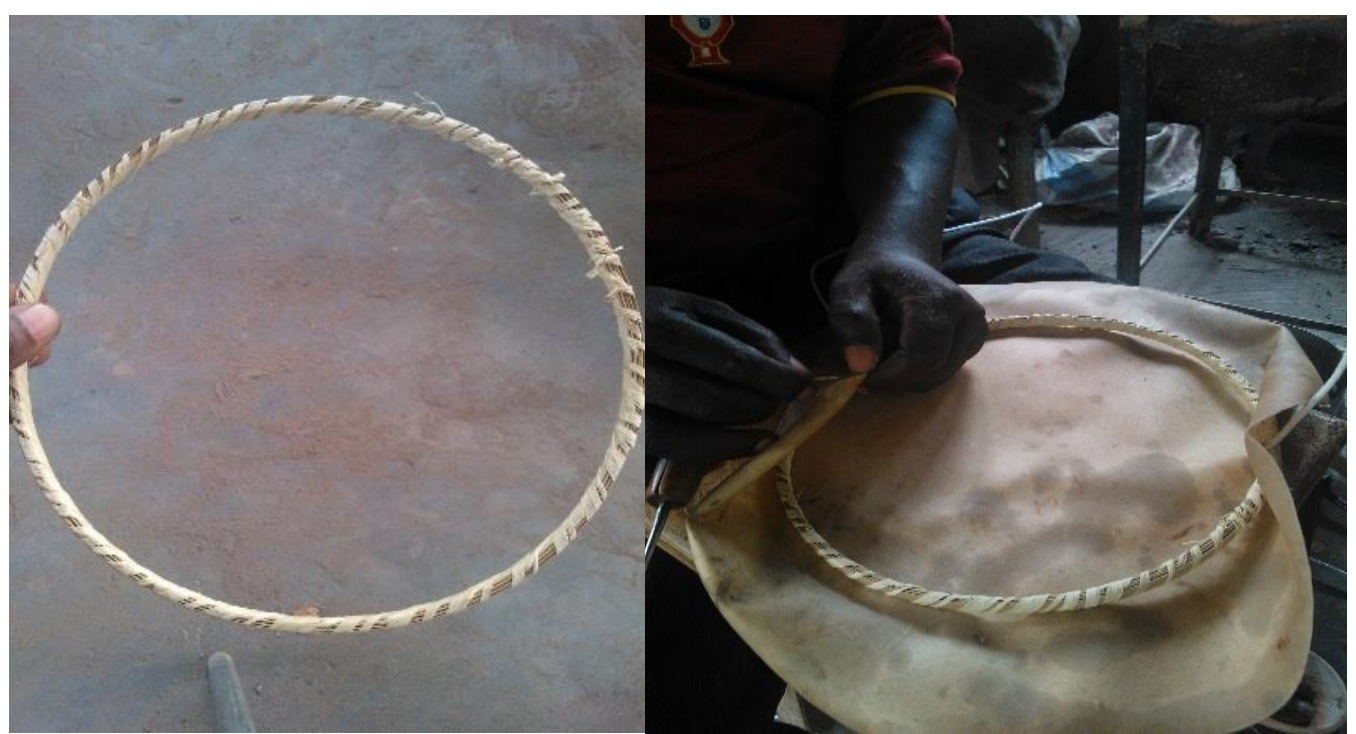

Fig 17:- raffia wrings

Fig 18:- animal skin being woven on the raffia ring

A ring was then made from raffia as shown in figure 17, and the skin was then sewn to it as in figure 18. The skins with the raffia rings and the twines in them was then place on the edges of the drum frames. The pegs were then inserted in to the peg holes through the twines in the usual fashion as shown in figure 19 and then driven with a mallet to stretch the skin. The skins were then trimmed and subsequently the twine as demonstrated in figure 20.

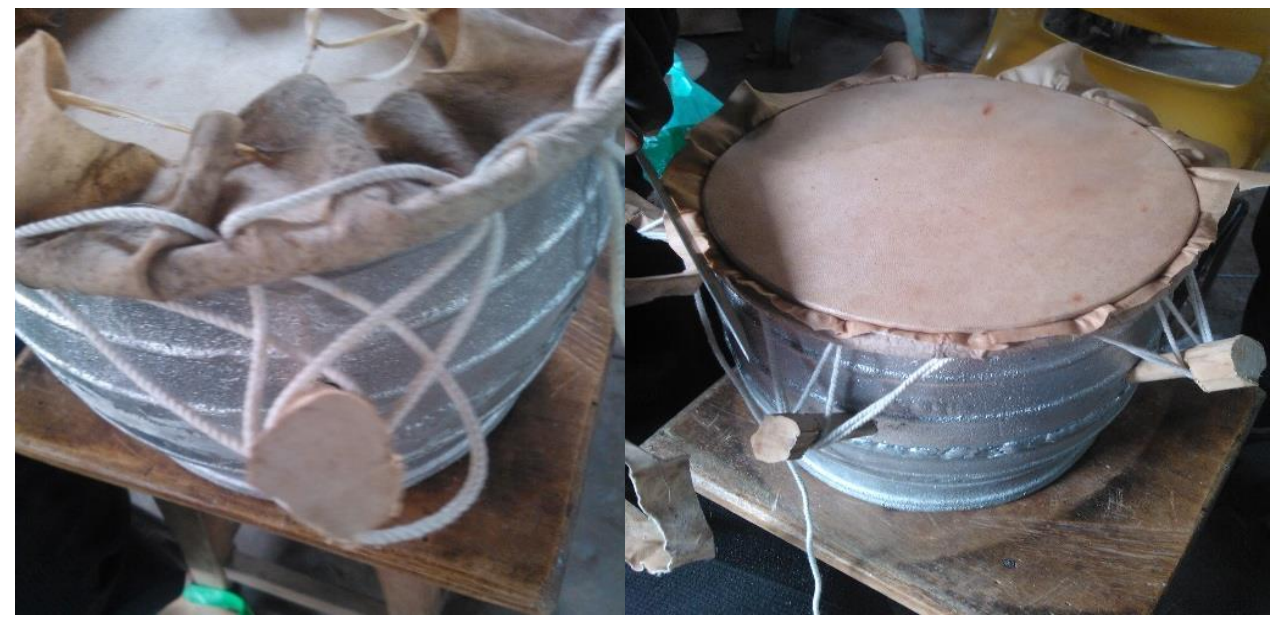

Fig 19: skin being weaved on the drum Fig 20: excess skin being cut off. 
The drums were then placed in the sun as shown in figure 21 to allow for dryness and also good sound. To improve the looks of the drum a black enamel paint was use to paint the middle of the drum as in figure 22, and them embellished with some adin kra symbol cut out from aluminium sheets as shown in figure 23

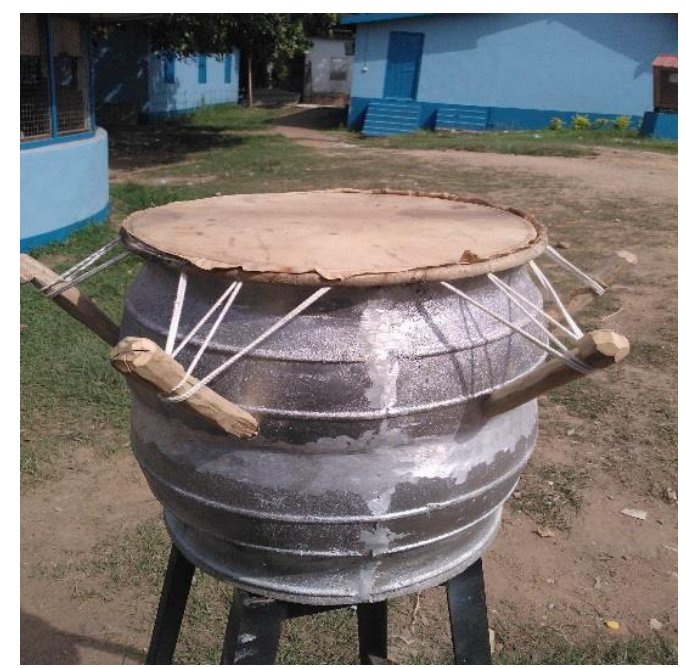

Fig 21:- drum being dried in the sun

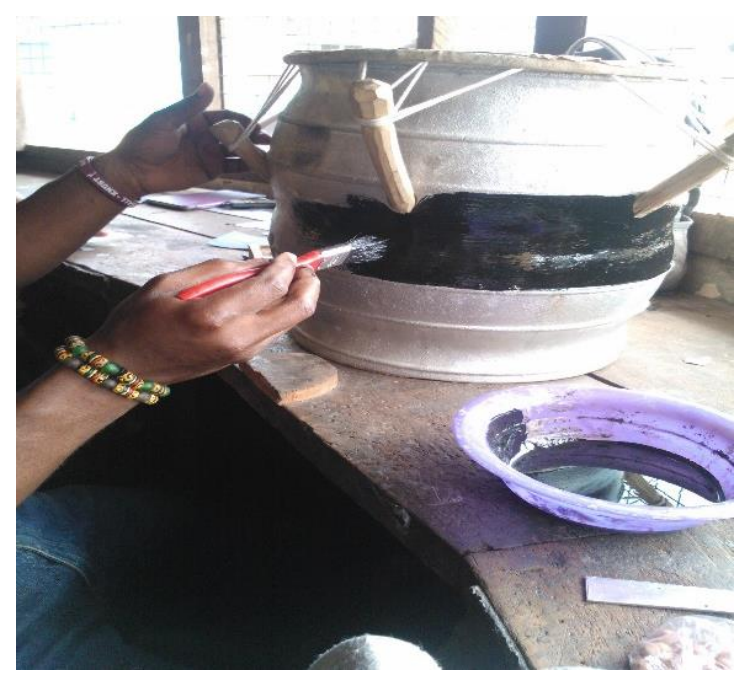

Fig 22:- middle belt of the drum being painted with oil based paint for decoration

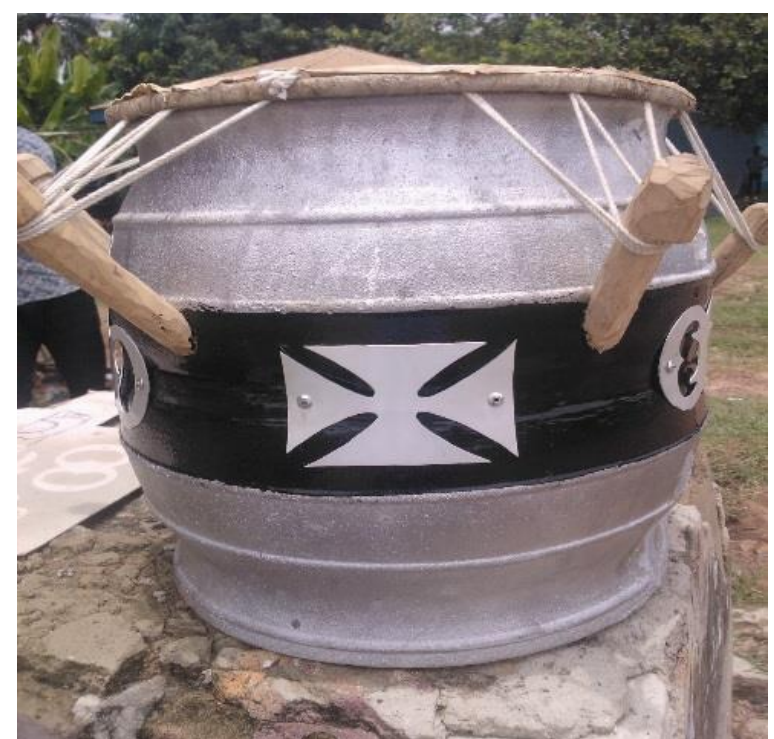

Fig 23: The final drum with riveted adinkra symbols 


\section{RESULTS AND DISCUSSION}

The two drums came out well with good sounds. As shown in figure 24, the natural aluminium colour made a good blend with the other materials and may not require any colouring of the entire frame except where decorative touches are required. A closer look at the drum in figure 25 reveals the riveted point as well as the natural textures of the materials. This is further displayed in figure 26 showing the bottom view. The resultant drum are discussed under with regards to their Strength and durability; Portability; sustainability of the design; ergonomics; mode of execution and equipment selection; and preservation.

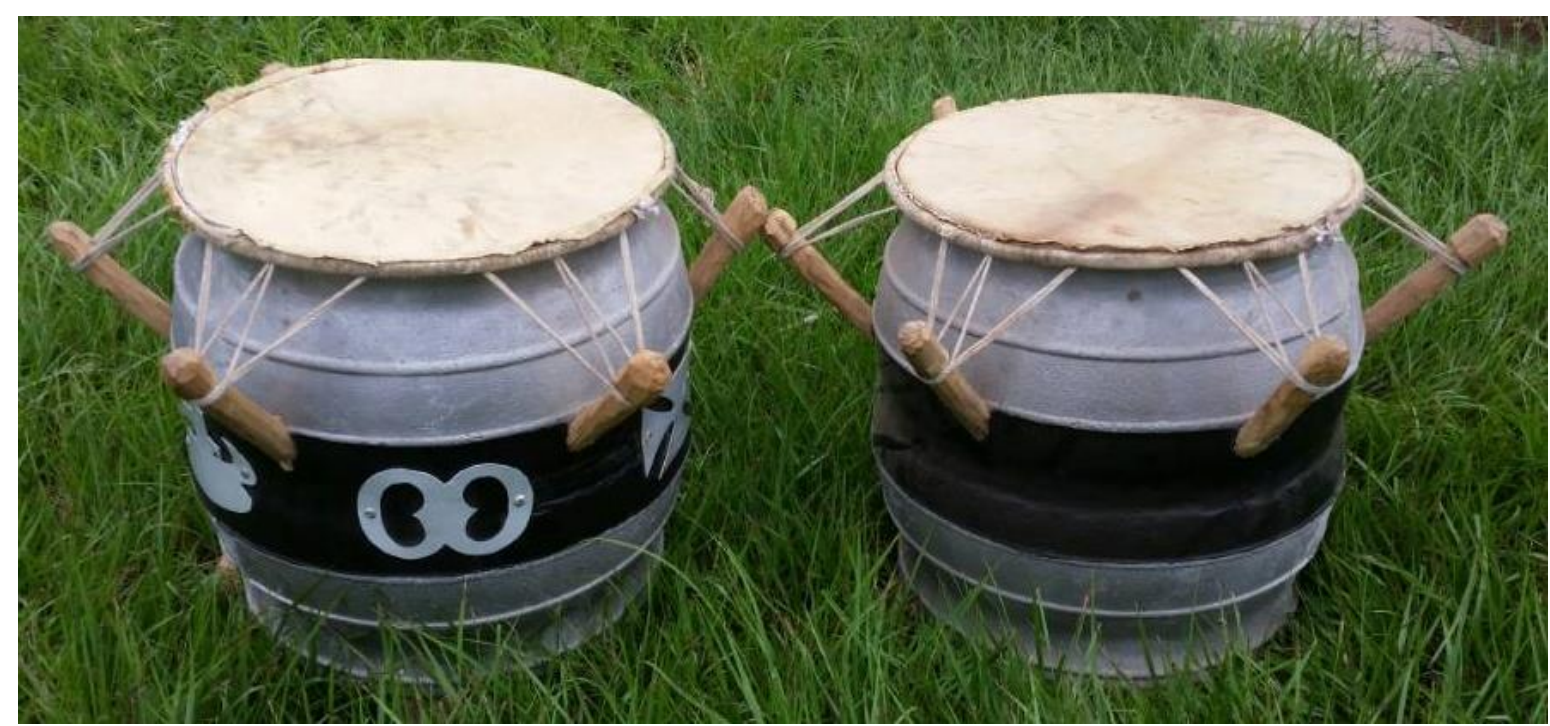

Fig 24:- The final pair of drums

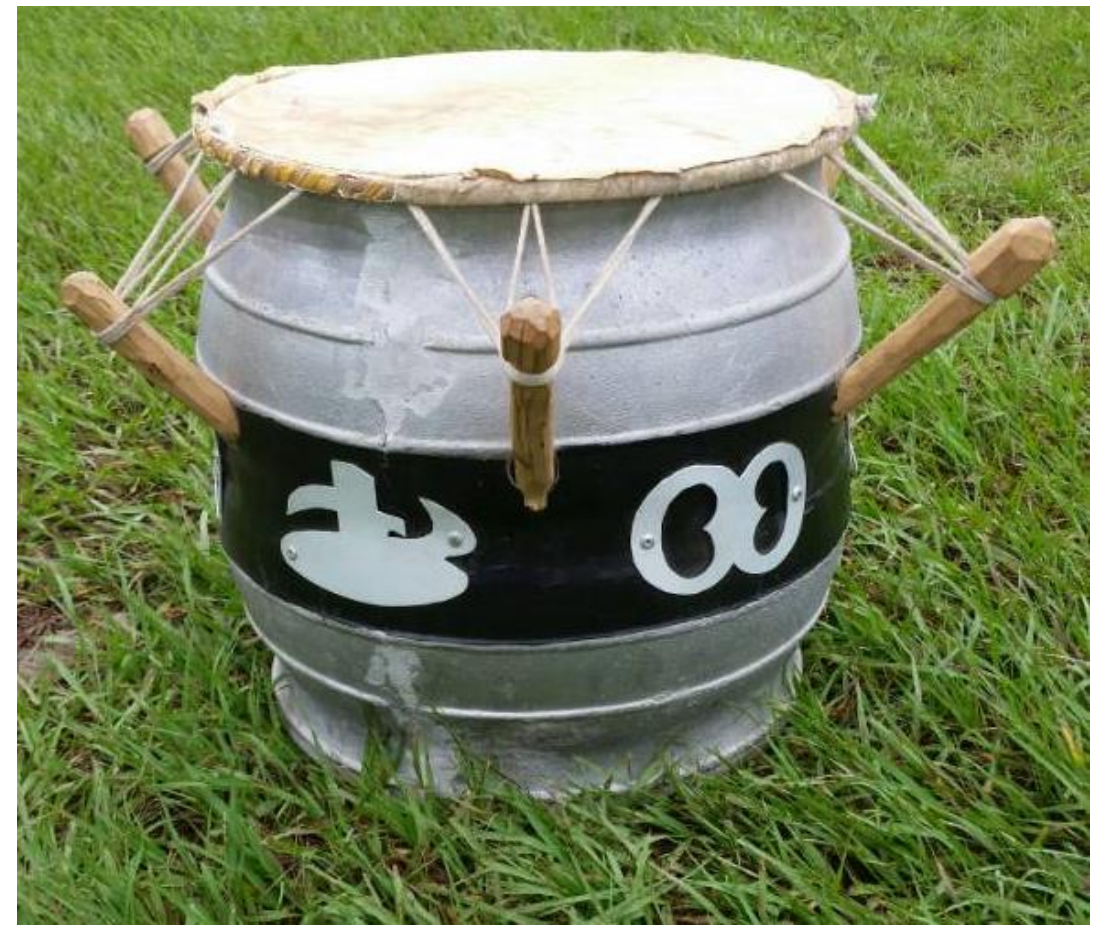

Fig 25:- A closer look at one of the pair of the finished drums 


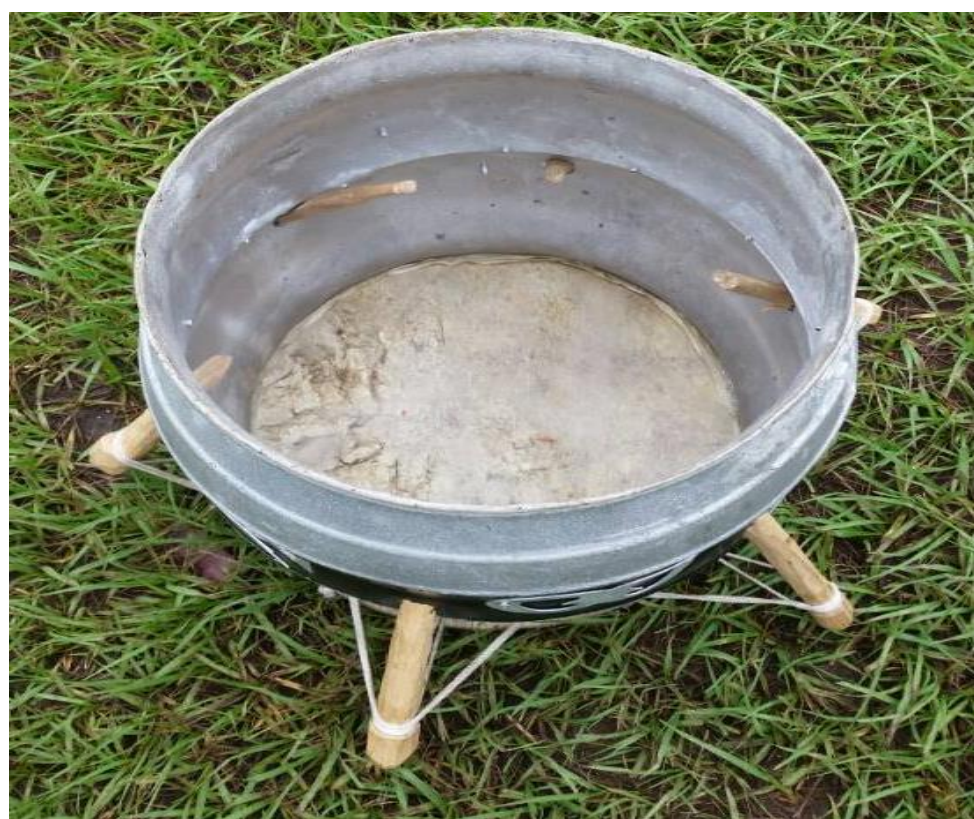

Fig 26:- The final drum being reverted with adinkra symbols

The strength of the resultant drum is much comparable to the wood. The aluminum shell is strong in relative terms with mood. Besides is friendly to the animal skin like wood and has an added advantage of withstanding temperatures below $660.3^{\circ} \mathrm{C}$ in times of fire.

The thickness of the aluminum shell is relatively lighter than the usual wood consequently lighter in weight. This makes the drums more potable than the heavy wood mass of the most popular drum making wood like Tweneboa Wood. Due to the nature of processes and materials chosen, the design is easy to relate to by the local artisan. the working processes are tailored to the local approach to making drums. Besides the nature of the drum especially the surface orientation is equivalent to a number of drums like the atumpan drum and the djembe drums. This also makes it friendly drummers who use such drums.

Most of the time drums are found to be hanging on the neck of people or being carried on the head each time it is being used in motion. So it has been notice that the weight of drums matter because carrying them may cause a negative physiological impact on the user in case if massive weight. in this regard, the aluminum caldron drum can be said to be user friendly due to its lighter weight.

Also, carving of drums depends heavily on timber, which happens to be an important forest resource that offers life support around the work. In this regard there are policies to minimize their exploitation. In effect this approach to drum making contributes sustainability to the drum making industry notwithstanding the forest. This makes it more environmentally friendly, because the forestry requirement in terms of the materials used are minimal. Apart from these the equipment employed were also less sophisticated for the purpose of adaptability by the local artisans. Also the preservation of the drums shells did not indulge an additional processes, but adapter the nature aluminium oxides of the surfaces of the caldrons obtained from casting. Less effort is therefore required to maintain the looks of the drums shells.

\section{CONCLUSIONS}

Apart from the simple steps and equipment required to for this project, the research experiment came with the realization that the variation in the use of the "Dadesen" in terms of sizes specification, cutting, and the selection and manipulation of the other materials may depend on the following:

$>$ Purpose of the drum.

$>$ Sound perspective.

$>$ Size of the drum.

$>$ Height of the drum.

In this respect, one has to know the purpose for producing the drum, such as for communication, entertainment, ritual purpose and medium by which the drum will be played. Also the sound to be produced has to be put into consideration regarding the pitch and the distance the sound will travel. This will also help in the selection of materials including the appropriate size of the "dadesen". For example, different skins may be required for different occasions of drum with regards to the quality of sound required but also the prestige that may be associated with certain class of skins.

Cast aluminium caldron though have not been used in the making of drums, its properties relates to different types of drums. Moreover, the weights of the caldrons comparatively, give room for portability. Furthermore, the outcome of this project is another demand for the local caldrons as an increment in the market share of the local artisans. Also it is also expects to stimulate interest in the use of metal castings as alternative for the making of drums to decrease the burden on the fast depleting forest. 


\section{RECOMMENDATIONS}

This concept is recommended as a sustainable approached to increasing the turnover of the local casting artisans to improve on their businesses. This is expected through the adaptation of the concept by drum producers who may consequently order more of the dadesen from the artisans who make them, to sustain their businesses and the industry for that matter. It is also recommended that, there should be a research into the different sizes of the dadesen in relation to different types of drums to widen the scope of their use. Moreover, the concept is recommended for further research towards the diversification of drum making materials, in order to support the timber: a buffer of nature towards the environment protection agenda among the world's sustainable development goals.

\section{REFERENCES}

[1]. Aluminium Bozen. (2015, March 11). Menu page. Retrieved from Alminnium bozen Web site: http://www.aluminiumbozen.com

[2]. benistoves.wordpress.com. (2011, November 7). benistoves. Retrieved from First Comes the Pot: https://benistoves.wordpress.com/first-comes-thepot/metal-spherical-pots-in-africa/

[3]. Hadjia, 2017 . The Aluminum Utensil Sizes [Interview] ( 25 october 2017 ).

[4]. Hannah, M., 2017. Materials Employed in Aluminum Utensil Production in Ghana [interview] Novemeber, 2017).

[5]. Eldridge, E. R. (2005). The impact of Deforestation on Drum Making in Ghana, West Africa. Knoxville: University of Tennessee.

[6]. Ganiho, M. A. (2017, october 15). Aluminum Utensil Sizes. (H. I. Timothy, Interviewer)

[7]. Ganiho, M. A. (2017, november 2). Types of Aluminum Utensil Produced in Ghana. (H. I. Timothy, Interviewer)

[8]. Hadjia. (2017, october 25). The Aluminum Utensil Sizes. (b. ansah, Interviewer)

[9]. Hannah, M. (2017, novemebr 23). Aluminum Utensil Sizes in Ghana. (A. Benjamin, Interviewer)

[10]. Ibrahim, M. T. (2017, october 15). Aluminum Utensil Sizes. (A. Benjamin, Interviewer)

[11]. Priscilla, M. (2017, october 12). Aluminum Utensil Sizes. (A. Benjamin, Interviewer) 